Geoscience and Remote Sensing Symposium (IGARSS), 2016 IEEE International. pp.5820-5822

http://archimer.ifremer.fr/doc/00377/48801/

(C) 2016 IEEE

\title{
Perspectives for directional spectra assimilation : Results from a study based on joint assimilation of CFOSAT synthetic wave spectra and observed SAR spectra from Sentinel-1A
}

\author{
Aouf L. ${ }^{1,{ }^{*}}$, Hauser D. ${ }^{2}$, Tison C. ${ }^{3}$, Mouche Alexis ${ }^{4}$ \\ ${ }^{1}$ Meteo France, Toulouse, France. \\ 2 UPMC, LATMOS, CNRS, UVSQ, 11 Blvd dAlembert, F-78280 Guyancourt, France. \\ ${ }^{3}$ CNES, 18 Ave Edouard Belin, F-31400 Toulouse, France. \\ ${ }^{4}$ IFREMER, Technopole Brest Iroise, F-29280 Plouzane, France. \\ * Corresponding author : L. Aouf, email address : lotfi.aouf@meteo.fr
}

Keywords : assimilation, surface ocean wave model, SAR, CFOSAT, forecast, surface ocean wave spectra 


\section{INTRODUCTION}

The assimilation of satellite wave observations plays a key role in the operational wave forecasting system of Météo-France. The assimilation system corrects efficiently the wave model errors, which are mainly related to the wind forcing. To ensure reliable marine security bulletins the assimilation system is upgraded by wave data provided by new satellite missions. Since 2010 improvements have been obtained for the parametrization of the dissipation by wave breaking [1] but there is still possible improvement for directional properties of swell. The assimilation of directional wave spectra such as those provided by the Synthetic Aperture Radar (SAR) can be very helpful in order to catch the best initial conditions of swell generated by storms. The wave forecasting system of Météo-France assimilated in operations SAR level 2 directional wave spectra provided by ENVISAT since March 2011 until the end of mission. Lessons from this experience showed that the assimilation of SAR directional wave spectra improves the normalized scatter index of the peak period of long waves larger than 10 seconds by $20 \%$ with respect to buoy data [2]. Since June 2015 SAR wave spectra from Sentinel-1A (S-1A) are globally provided by the European Space Agency (ESA). The wave mode in S-1A has two incidence angles. The imagettes (size of 20 by $20 \mathrm{~km}$ ) on the same incidence angle are separated by $200 \mathrm{~km}$.
Swath alternates incidence angles between near range and far range which are $23^{\circ}$ and $36.5^{\circ}$, respectively. The retrieved level 2 directional wave spectra are described in 60 frequencies up to $0.22 \mathrm{~Hz}$ and 72 directions by a step of $5^{\circ}$. The goal of this work is firstly to evaluate the impact of the assimilation of SAR spectra from S-1A in the wave model MFWAM. Secondly the impact of using several sources of wave data such as altimeters, SAR spectra and CFOSAT synthetic spectra is investigated in the period of analysis and forecast. We recall that the instrument SWIM of CFOSAT will provide directional wave spectra for waves larger than about $70 \mathrm{~m}$ in wavelength, while the SAR has a cut-off at roughly $200 \mathrm{~m}$ in wavelength.

\section{METHODOLOGY}

The operational wave forecasting system of MétéoFrance is composed of the wave model MFWAM and the assimilation system using the wave observations from satellites. The model MFWAM is based on the ECWAM code with a dissipation by wave breaking developed by Ardhuin et al. [1] and a swell damping term induced by the air friction at the sea surface. The wave model MFWAM has been upgraded in November 2014 with major improvements thanks to the My wave European FP7 research project [3]. The assimilation technique is based on an optimal interpolation technique with, for spectral information, assimilation of wave main parameters (significant wave height, mean period and direction) of up to 3 partitions of the full two-dimensional spectrum [4]. 
Synthetic directional spectra from CFOSAT are obtained from the simulator FAWASSI developed at the French Space Agency (CNES) in 2012. This simulator uses as input an ocean surface reconstructed from directional wave spectra provided by the wave model MFWAM. As an output the simulator FAWASSI provides synthetic spectra as they are seen by the real aperture radar SWIM of CFOSAT. The run of the wave model MFWAM driven by analysed winds from ECMWF gives at CFOSAT orbit tracks the input directional spectra for FAWASSI.

In this study several runs of the model MFWAM have been performed in order to evaluate the contribution of each wave observations (altimeters, SAR and CFOSAT). To make sure that the synthetic spectra and the first guess of the wave model are uncorrelated, 3-day forecast winds from ECMWF atmospheric model is used to drive the model runs. The assimilation is performed every 6 hours. Also a baseline run of the model without assimilation is performed.

\section{RESULTS AND DISCUSSIONS}

In our previous work [2] we have demonstrated that only the assimilation of directional wave spectra induces a significant impact on peak wave period of swell dominant sea state, as illustrated in figure 1. This latter showed also when we assimilate conjointly CFOSAT synthetic spectra, Envisat wave spectra and altimeters the scatter index of peak period is improved regarding to the use of Envisat and altimeters.

The assimilation of SAR wave spectra from S-1A shows a significant impact in the forecast period, as illustrated in figure 2. The difference of mean wave period can reach after 1 -day forecast about 1.5 seconds as indicated in the eastern part of the pacific ocean. This is related to the intense hurricane season in the east pacific on September 2015. The validation of the results with independent wave data such altimeters and buoys has been performed. Figure 3 shows the variation of the normalized scatter index of significant wave height in the forecast period. The smaller the scatter index is, better the performance of the system is. It is clearly indicated that when we use both altimeters and SAR directional wave spectra the impact is more pronounced. We can also see that the impact stays efficient until 3-day forecast. Results on model runs with both S-1A and CFOSAT spectra will be commented in the final paper. Further comparison with buoys data will be also discussed.

\section{CONCLUSIONS}

With a low cut-off for the directional wave spectra CFOSAT will impact both mixed sea and swell. The complementary use of CFOSAT and SAR wave spectra will enhance the impact of the assimilation and therefore induce a more accurate sea state. The CFOSAT mission is on one hand a big challenge for operational wave forecasting system, and on the other hand a good opportunity for wave modellers in order to improve the source and dissipation terms in the wave model.

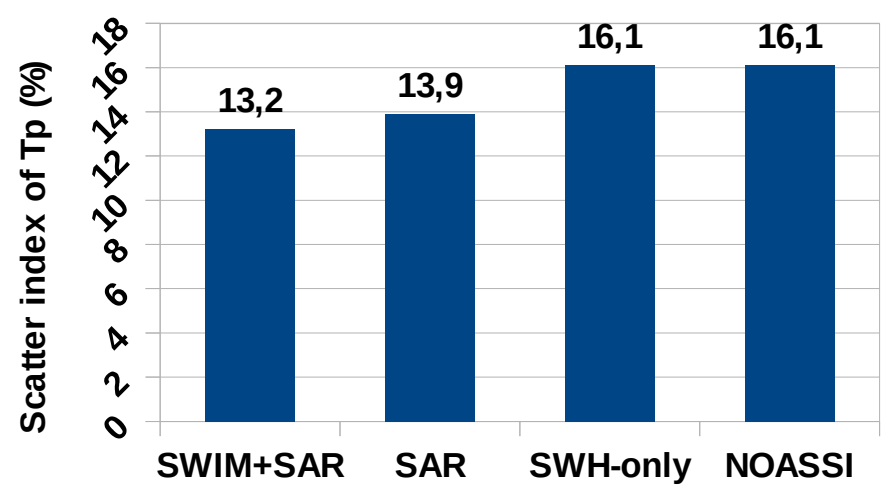

Figure 1. Normalized scatter index of peak period (in \%) for several runs with respect to NDBC buoys. SWIM+SAR, SAR, SWH-only and NOASSI stand for the assimilation of all satellites (CFOSAT and Envisat spectra and altimeters),

the assimilation of Envisat spectra and altimeters, the assimilation of altimeters only, and the control run without assimilation. 


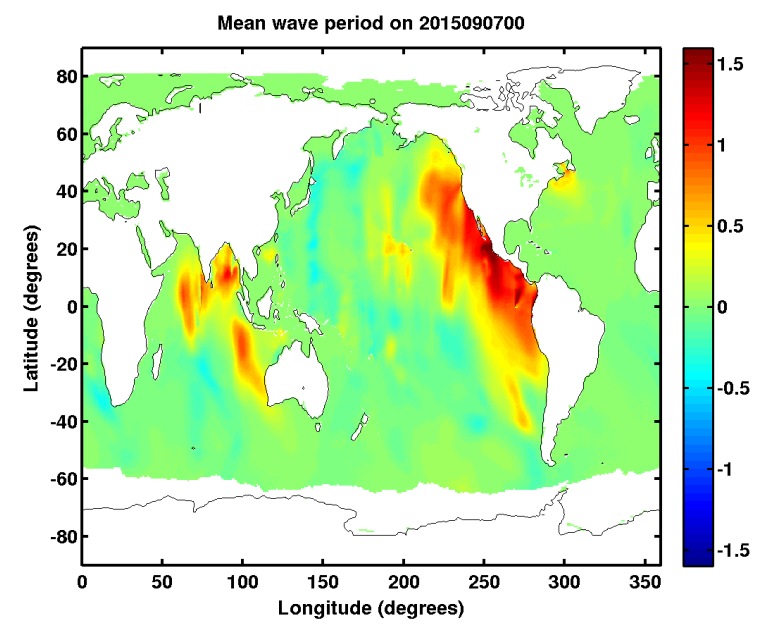

Figure 2. Difference of mean wave period (in seconds) from the wave model MFWAM with and without assimilation of Sentinel-1A wave spectra after 1-day forecast on September 7, 2015 at 0:00 UTC.

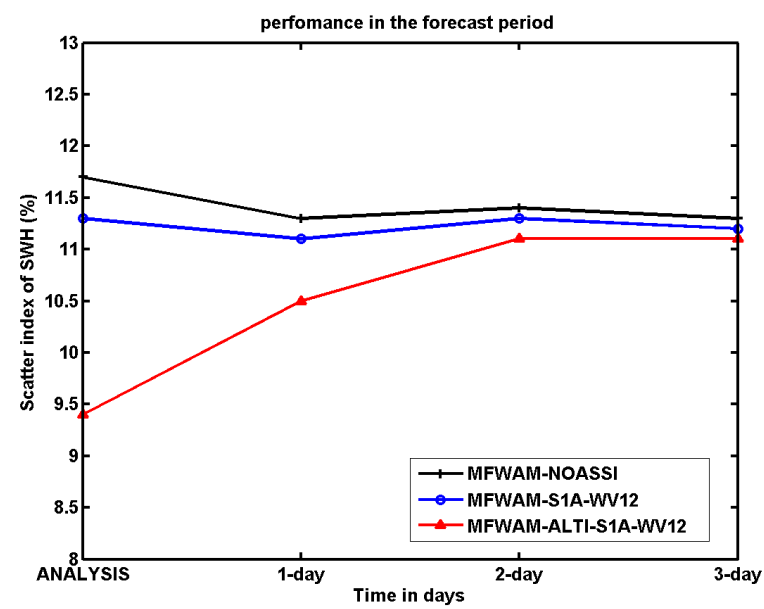

Figure 3. Variation of the normalized scatter index (in $\%)$ of significant wave height in the forecast period based on comparison with altimeters (Jason-2 and Saral).

Triangles, circles and pluses stand for runs of the model MFWAM with assimilation of altimeters and SAR spectra from $S-1 A$, with assimilation of SAR spectra from S-1A only and without assimilation, respectively.

\section{REFERENCES}

[1] Ardhuin F., R. Magne, J-F. Filipot, A. Van der Westhyusen, A. Roland, P. Quefeulou, J. M. Lefèvre, L. Aouf, A. Babanin and F. Collard : Semi empirical dissipation source functions for windwave models : Part I, definition and calibration and validation at global scales. Journal of Physical Oceanography, 40(9), pages 1917-1941 2010.
[2] L. Aouf, J-M. Lefèvre, On the assimilation of ASAR directional wave spectra in the operational wave model MFWAM. Proceedings of workshop SEASAR 2012, Tromso, Norway.

[3] P. Janssen, O. Breivik, L. Aouf, L. Cavaleri, K. Christiensen, G. Korres, final report of work package I of My wave project, 2014.

[4] L. Aouf, J-M. Lefèvre, D. Hauser, Assimilation of directional wave spectra in the wave model WAM : an impact study from synthetic observations in preparation to the SWIMSAT satellite mission. Journal of Atmospheric and Oceanic Technology. Vol. 23, No. 3, pages 448-463, 2006. 